Thorax 1985;40:152-153

\title{
Aberrant origin of the left coronary artery with associated aortic stenosis
}

\author{
ROBIN J NORTHCOTE, B SETHIA, JOHN B McGUINNESS
}

From the Department of Medical Cardiology, Victoria Infirmary, Glasgow

Many variations of the aortic origin of the coronary arteries are recognised.' Until recently these have been reported infrequently and usually discovered during necropsy. ${ }^{2}$ The widespread use of coronary arteriography, however, has led to more frequent detection of the anomalies during life. Anomalous origin of the left coronary artery from the right sinus of Valsalva is rare, having been found in one series in 1:2000 angiograms. ${ }^{3}$ It is important that this condition is recognised, as origin of the coronary arteries from the right sinus of Valsalva is associated with an increased risk of sudden death ${ }^{24}$ and may have specific implications for the surgeon when associated with valvular or congenital heart disease. We report such a case associated with critical aortic stenosis. Although several investigators have reported anomalous left coronary artery origin and mitral valve disease,$^{5}$ the association of anomalous left coronary artery origin and appreciable aortic stenosis is exceedingly rare.

\section{Case report}

A 73 year old man experienced retrosternal chest pain, followed by a syncopal episode, while driving his car. On admission to hospital he gave a history of angina pectoris extending over several years and of lightheadedness and blackouts that had developed recently. On examination he was found to have the physical signs of aortic stenosis. Chest radiography showed moderate left ventricular prominence, pulmonary congestion, and calcification of the aortic valve. The electrocardiogram showed left ventricular hypertrophy with strain pattern. He gave no history of rheumatic fever and no rise in cardiac enzymes was observed in the following 72 hours. An echocardiogram showed a thickened, stenotic aortic valve. At cardiac catheterisation the left ventricle could not be entered owing to severe aortic stenosis and aortic valve calcification. Repeated attempts were made to catheterise the left coronary artery without success. An aortic root angiogram showed filling of the right coronary artery only. Right coronary arteriography (fig 1) showed anomalous origin of the left main coronary artery from the right sinus of Valsalva and a large, dominant right coronary artery.

The patient was referred for aortic valve replacement. At operation he was found to have a large right coronary artery with multiple collateral vessels supplying the left ventricle. The left coronary sinus was normal, but the left

Address for reprint requests: Dr RJ Northcote, Department of Medical Cardiology, Victoria Infirmary, Glasgow G42 9TY.

Accepted 25 October 1984 coronary ostium was absent. The origin of the right coronary artery was in the normal position and just lateral to this was a smaller opening, from which the anomalous left coronary artery supplying the hypoplastic left coronary system originated (fig 2). The aortic valve was heavily calcified and stenotic. It was therefore replaced with a $23 \mathrm{~mm}$ Björk-Shiley aortic prosthesis. The patient was discharged 10 days after surgery and was well when last reviewed, six months after operation. In particular, he had no anginal symptoms and his exercise tolerance is now normal.

\section{Discussion}

Coronary artery anomalies usually present as an incidental finding during coronary arteriography or during postmortem examination. ${ }^{6}$ A knowledge of variations in the coronary anatomy is important if myocardial protection is to be adequate during surgery for a coexisting lesion-in this case, aortic stenosis. The combinaton of the anomalous origin of the left coronary artery from the right sinus of Valsalva and aortic stenosis is rare. Although there is a reported high incidence of valvular heart disease with an anomalous origin of the coronary arteries ${ }^{13}$ this may be due to the fact that coronary arteriography is performed more frequently in subjects with valve lesions. Kimbiris et $a l,{ }^{3}$ in a series of 7000 angiograms, found nine patients with associated aortic valve disease and coronary artery anomaly, but in none of these did both coronary arteries arise from the right sinus of Valsalva. We are aware of only one previously reported case of aortic stenosis with both coronary arteries originating from the right sinus of Valsalva. ${ }^{2}$

A left coronary artery originating from the right sinus of $D$ Valsavla is associated with sudden death, especially when the aberrant vessel courses between the aorta and the pul- $\mathrm{N}$ monary artery. ${ }^{2}$ Such anomalies usually present in adoles- $\sigma$ cence and the diagnosis is made at necropsy. Whereas in $\mathrm{N}$ younger patients coronary artery surgery may be under- $\mathrm{N}$ taken to prevent sudden death, management in older patients should be directed at relief of symptoms, as this group do not appear to be at risk of sudden death. An 0

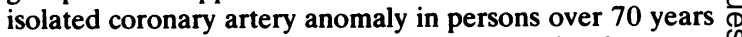
of age has been reported infrequently previously, as an ? incidental finding at postmortem examination. ${ }^{78} \mathrm{We}$ are $\square$ unable to find a case documented during life in this age group. As in our case, hypoplasia of the coronary circula- $\mathbb{D}$ tion distal to the congenital abnormality has been noted ${ }^{2} \frac{\Phi_{\vec{D}}}{\mathbb{D}^{2}}$ and formed part of the rationale for not performing a coronary artery bypass operation with a graft to the 


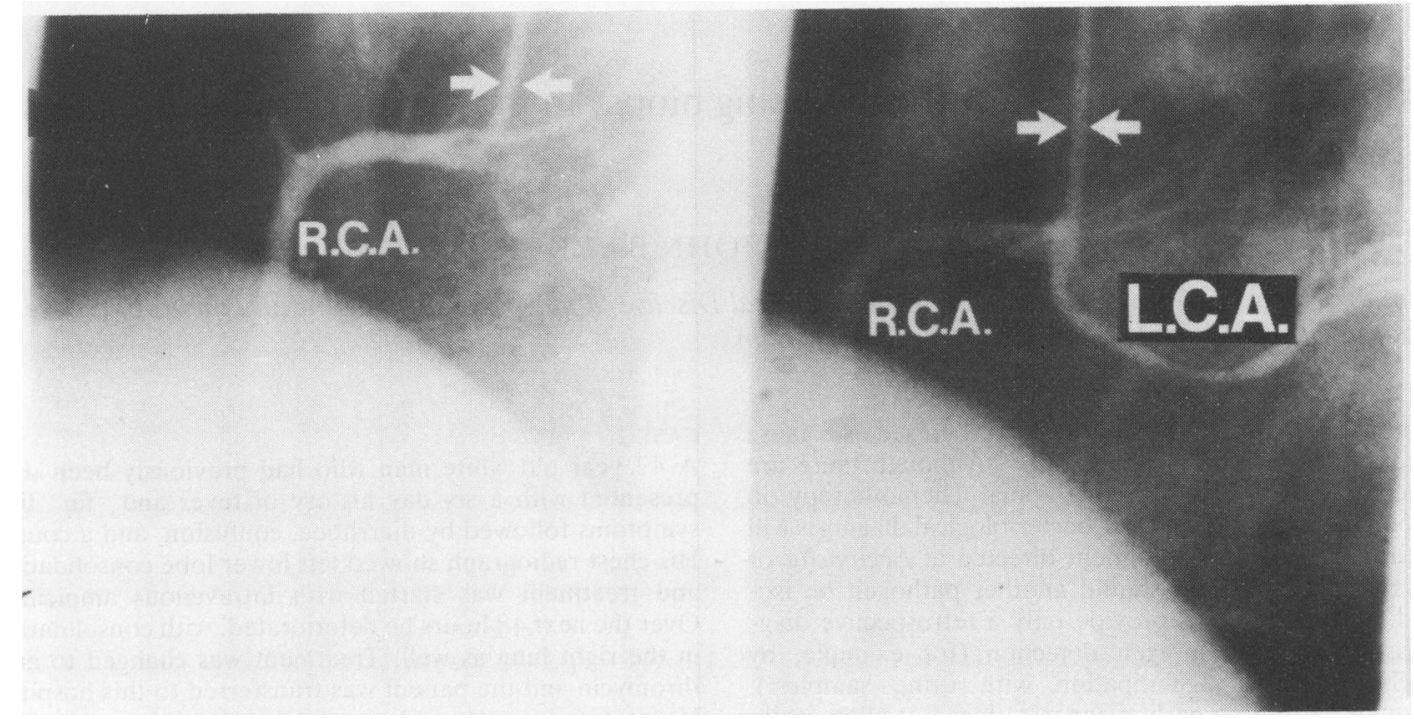

Fig 1 Selective coronary arteriography of $(A)$ the dominant right coronary artery $(R C A)$ and $(B)$ the adjacent anomalous left coronary artery $(L C A)$, with the catheter arrowed in each case. Note the anomalous left coronary artery supplying a hypoplastic left coronary circulation, and with an area of narrowing in its mid portion. There is also retrograde filling of the right coronary artery.

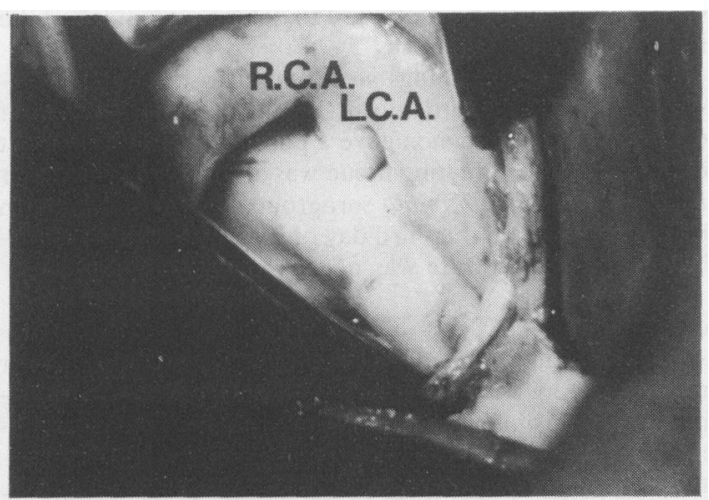

Fig 2 Aortic root at operation showing the right sinus of Valsalva with separate ostia for the right coronary artery $(R C A)$ and the left coronary artery $(L C A)$.

atherosclerotic region of the aberrant left coronary artery, in our patient.

Unrecognised coronary artery anomalies may lead to problems when cardiac surgery is performed for a coexisting lesion, ${ }^{9}$ as the anomalous coronary artery can be excluded from perfusion and myocardial protection impaired. In our case, cardiac surgery proved to be a safe procedure that resulted in symptomatic relief for the patient. We support the view that grafting of small vessels in this condition is contraindicated, although when apprec- iable atherosclerosis is present a coronary artery bypass graft may be necessary.

We acknowledge the assistance of Professor DJ Wheatley in the preparation of this paper.

\section{References}

1 Chairman BR, Lesperance J, Saltiel J, Bourass MG. Clinical, angiographic, and hemodynamic findings in patients with anomalous origin of the coronary arteries. Circulation 1976;53:122-31.

2 Liberthson RR, Dinsmore RE, Bharati S, et al. Aberrant coronary origin from the aorta: diagnosis and clinical significance. Circulation 1974;50:774-9.

3 Kimbiris D, Iskandrian AS, Segal BL, Bemis CE. Anomalous aortic origin of coronary arteries. Circulation 1978;58:606-15.

4 Jokl E, McClellan JT, Williams WC, Gouze FS, Bartholomew RD. Congenital anomaly of the left coronary artery in young athletes. Cardiologia 1966;49:253-8.

5 Newton MC, Burwell LR. Single coronary artery with myocardial infarction and mitral regurgitation. Am Heart $J$ 1978;95: 126-7.

6 Ogden JA. Congenital anomalies of the coronary arteries. Am J Cardiol 1970;25:474-9.

7 Ogden JA, Goodyer AVN. Patterns of distribution of the single coronary artery. Yale J Biol Med 1970;43:11-21.

8 Cheitlin MD, DeCastro CM, McAllister HA. Sudden death as a complication of anomalous left coronary origin from the anterior sinus of Valsalva. Circulation 1974;50:780-7.

9 Logenecker CG, Reemtsma K, Creech O jun. Surgical implications of single coronary artery: a review and two case reports. Am Heart J 1961;61:382-6. 